\title{
Age-related differences in the magnitude of pattern-contingent color aftereffects
}

\author{
NANCY B. BOLOGNA, JAMES G. MAY, and SETH KUNEN \\ University of New Orleans, New Orleans, Louisiana
}

\begin{abstract}
Pattern contingent color aftereffects were measured using a color cancellation technique in 6-, 8-, 10-, and 20-year-old subjects. Postadaptation test conditions involved immediate testing or testing after subjects were blindfolded for $60 \mathrm{~min}$ between adaptation and posttests. The 6- and 8-year-old subjects exhibited color aftereffects whose magnitude was significantly greater than those observed in 10- and 20-year-olds. In addition, aftereffect magnitude was significantly greater after $60 \mathrm{~min}$ in the dark than when subjects were tested immediately. These findings are discussed in terms of their implications for the development of perceptual learning.
\end{abstract}

The human visual system is assumed to develop adult levels of anatomical complexity and perceptual functioning quite early in life. Myelinization and dendritic branching are relatively complete between the ages of 6 months and 1 year (Karmel \& Maisel, 1975). The periphery of the infant's retina appears to be fully developed soon after birth, the macula is well developed by approximately 11 months (Abramov, Gordon, Hendrickson, Hainline, Dobson, \& LaBossiere, 1982), and adult levels of accommodation (Salapatek, 1975) and acuity (Marg, Freeman, Pheltzman, \& Goldstein, 1976) are achieved between 4 and 6 months of age. Stereopsis is evidenced in infants as young as $31 / 2$ months (Fox, Aslin, Shea, \& Dumais, 1980) and appears to reach adult levels by age 3 to 4 years. There is evidence that by 1 year of age children have welldeveloped color vision (Bornstein, 1981) and welldeveloped pattern processing abilities (Movshon \& Van Sluyters, 1981; Pirchio, Spinelli, Fiorentini, \& Maffei, 1978). Because the development of these basic visual capabilities appears to be complete within the first few years of life, research with older children has concentrated on the development of cognitive processes and few studies have been concerned with basic perceptual phenomena in school-age children.

Coren and Girgus (1978) summarized the findings of 36 developmental studies concerned with seven different illusions. Generally, it was shown that the strength of the illusions increased as age decreased. While Coren and Girgus suggested that their results may have been due to optical factors or retinal interactions influencing contrast for children, studies have found no difference in the modulation transfer functions of children of this age and adults (Moskowitz, Skarf, \& Sokol, 1983; Pirchio et al., 1978). Recently, Meyer, Coleman, Dwyer, and Lehman (1982), using a McCollough paradigm, obtained patterncontingent color aftereffects in children, and reported that

The authors' mailing address is: Department of Psychology, University of New Orleans, New Orleans, LA 70148. first and third graders experienced the same percentage of aftereffects as did adults. However, the design of the study and the apparatus used did not allow the aftereffects experienced by the children and adults to be quantified.

The pattern-contingent color aftereffects first described by McCollough (1965) have been studied extensively in adults. (For a review, see Skowbo, Timney, Gentry, \& Morant, 1975.) The color-cancellation procedure employed in the present study is similar to one developed by Riggs, White, and Eimas (1974). It has the advantage of allowing the measurement of aftereffect magnitude and mitigates response bias typically associated with verbal report techniques. In a series of experiments (Kaufman, May \& Kunen, 1981; Kunen \& May, 1980; May, Agamy \& Matteson, 1978; May \& Matteson, 1976; May, Matteson, Agamy \& Castellanos, 1978) using checkerboard adaptation stimuli and grating test stimuli, it has been well established that pattern-contingent color aftereffects are mediated by the fundamental Fourier components of such stimuli in adults. One of the purposes of the present study was to determine whether young children show similar aftereffects, and to compare the magnitude of such aftereffects across a wide range of ages.

One of the most striking aspects of pattern-contingent aftereffects is that they appear to be quite long lasting (Jones \& Holding, 1975; MacKay \& MacKay, 1975; Riggs et al., 1974) and decay only if subjects are allowed postadaptation visual experience (Holding \& Jones, 1975; MacKay \& MacKay, 1975; Skowbo, Gentry, Timney, \& Morant, 1974). A second purpose of the present study was to determine if age-related differences in the decay of aftereffect magnitude exist.

\section{METHOD}

\section{Subjects}

Sixty-four subjects with visual acuity of at least 20/25 and normal color vision (screened with Ishihara's test) participated. Sixteen subjects were first graders (mean age $=6$ ), 16 were third graders (mean age $=8$ ), 16 were fifth graders (mean age $=10$ ), and 16 were college students (mean age $=20$ ). None of the subjects had any knowledge 
of pattern-contingent color aftereffects and all were naive as to the hypothesis under investigation.

\section{Apparatus}

The adaptation and test equipment have been described in a number of previous publications (Kaufman et al., 1981; Kunen \& May, 1980; May, Agamy, \& Matteson, 1978; May, Matteson et al., 1978). The test apparatus consisted of a small box with a binocular viewing aperture at one end and a rear-projection screen, $47.5 \mathrm{~cm}$ from the aperture, at the other end. No light, other than the light from the rear-projection screen, could enter the box. The test panel was divided into right and left panels, and was presented (on the rear-projection screen) by a Kodak Carousel projector. The left panel of the test slide contained vertical gratings, and the right panel contained oblique gratings sandwiched together with orthogonally oriented Polaroid material. The slide was projected, in order, through a piece of heat glass, a $0.5 \mathrm{log}$ neutral density filter, and a color-compensating filter (CCF) before striking the rearprojection screen. The CCF was composed of $6.25-\mathrm{mm}$ squares of magenta (Wratten CC20M) and green (Wratten CC30G) gelatin filters sandwiched together with 6.25 -mm squares of orthogonally oriented Polaroid material. The magenta and green squares formed a checkerboard pattern. By manually rotating the CCF clockwise (counterclockwise) while viewing the rear-projection screen, the subject could add magenta (green) light to the vertical lines while adding green (magenta) to the oblique lines. Thus, manipulation of the CCF allowed the subject to adjust the amount of magenta and green light in each panel of the test field. The gratings were presented at $65 \%$ contrast with a spaceaveraged luminance of $0.7 \mathrm{~cd} / \mathrm{m}^{2}$.

The adaptation apparatus consisted of a second Kodak Carousel projector, a standard viewing screen, and two adaptation slides. The two slides were composed of checkerboards, one normally oriented (squares) and one tilted at a $45^{\circ}$ angle (diamonds). Depending on the adaptation condition, the checkerboards were mounted with either a magenta (Wratten 32) or a green (Wratten 53) gelatin filter. The stimulus field was $22.5^{\prime \prime}$ square, at a distance of 106" from the subject, yielding adaptation stimuli with a fundamental spatial frequency of 3 cycles/deg. The space-averaged luminance of the adaptation stimuli was $8.2 \mathrm{~cd} / \mathrm{m}^{2}$.During presentation, the two adaptation stimuli were alternated every $5 \mathrm{sec}$, with an interstimulus interval of less than $250 \mathrm{msec}$. Within each test condition, half of the subjects ( $n=4)$ were randomly assigned to adapt to magenta diamonds and green squares; the other half were assigned to adapt to magenta squares and green diamonds.

\section{Procedure}

Each subject was tested individually. The subject first viewed the test stimulus while the experimenter turned a knob that rotated the CCF. The subject was instructed to notice how the colors in each panel changed as the CCF was rotated, and to note when both halves of the visual field appeared to be the same color. The subject was then given 10 trials to determine a color match betwen the two panels of the test stimulus. Prior to each trial, the experimenter set the CCF a random distance in either direction from the objective match point, and the subject was instructed to turn the knob in the opposite direction until he or she judged the panels to have the same hue.

During the adaptation phase, each subject was seated and a chinrest was used to assure proper head position. The subject was instructed to keep the checkerboards clearly focused. To prevent the formation of afterimages, the subject was also instructed to move his or her eyes around the central two-thirds of the checkerboard field. The experimenter observed the subject during this phase and prompted eye movements when necessary. (It should be noted, however, that the tendency for subjects experiencing prolonged visual stimulation of this sort is to move their eyes to prevent fatigue.) Total adaptation time was $15 \mathrm{~min}$.

Subsequent to adaptation, half of the subjects in each age group were tested immediately. The other half were blindfolded for $1 \mathrm{~h}$ prior to postadaptation testing. This delay condition was included to determine if passive decay of aftereffects was more rapid in children than in adults. Postadaptation testing was carried out using the same procedures as those employed in preadaptation testing.

\section{RESULTS}

The dependent measure for each subject was the difference between the mean preadaptation and mean postadaptation match points. As explained in greater detail elsewhere (Kaufman et al., 1981; Kunen \& May, 1980; May, Agamy, \& Matteson, 1978; May, Matteson et al., 1978), if positive values were obtained, it meant that subjects had color aftereffects associated with the fundamental Fourier components of the stimuli, whereas negative values implied color aftereffects associated with the edges of the stimuli. The mean aftereffect magnitudes for each of the four age groups in the immediate and delayed test conditions are presented in Figure 1. Note first that under all conditions, color aftereffects are positive and significantly different from zero. For the immediate condition, the youngest subjects exhibited the largest mean aftereffects, whereas the adults' mean aftereffects were lowest. For the delayed condition, the relationship between age and aftereffect followed a somewhat different trend. The 8year-old group showed the greatest aftereffect magnitude, followed by the 6-year-olds, the 10-year-olds, and the adults. In all but the adult groups, the delayed condition produced aftereffects of greater magnitude than did the immediate condition. This difference was greatest in the 8-year-old group, however.

The data were submitted to a $2 \times 4$ between-groups analysis of variance. The decrease in aftereffect magnitude with age $[F(3,56)=4.54]$ and the difference between

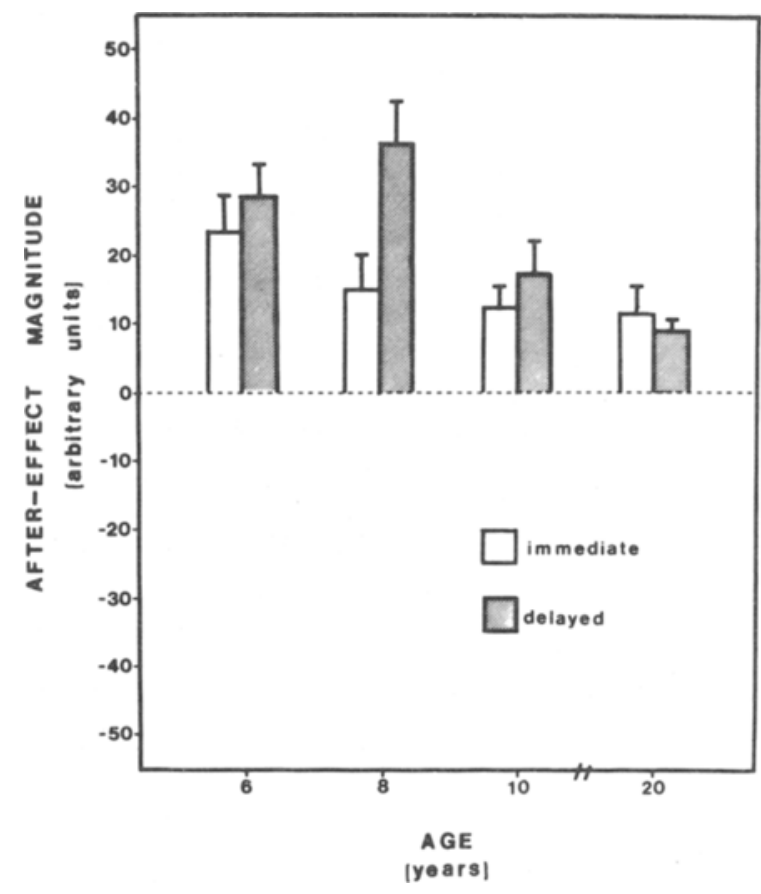

Figure 1. Mean aftereffect magnitude as a function of age for immediate (open bars) and delayed (stippled bars) test conditions. Vertical lines denote \pm 1.0 S.E. 
aftereffects for the immediate and delayed conditions $[F(1,56)=4.15]$ were significant beyond the .05 level of confidence. The interaction did not acheive significance $(p<.15)$. Tukey comparisons of different age groups revealed that the aftereffect magnitude for the 6- and 8 -year-olds were significantly greater than those of the adults.

\section{DISCUSSION}

These results are in general agreement with those of previous investigations employing checkerboard adaptation stimuli and grating test stimuli (Kaufman et al., 1981; Kunen \& May, 1980; May, Agamy, \& Matteson, 1978; May, Matteson et al., 1978). As expected, in both children and adults, pattern-contingent color aftereffects were mediated by the fundamental Fourier components rather than the edges of the patterns employed. The present findings also support the contention of Meyer et al. (1982) that children, as well as adults exhibit pattern-contingent color aftereffects, but these results suggest that significant quantitative differences exist. Aftereffect magnitude was significantly greater for younger observers. This suggests that the mechanisms that mediate these adaptational effects may be more sensitive in younger children.

The fact that aftereffect magnitude was significantly greater after $1 \mathrm{~h}$ of postadaptation darkness was somewhat unexpected but not unprecedented. Previous reports (McKay \& McKay, 1975, 1977) have indicated that pattern-contingent aftereffect magnitude is somewhat greater after about $1 \mathrm{~h}$ of darkness interposed between inspection and test. The amount of difference between immediate and delayed conditions did not interact with age, but most of the difference appears to occur in the 8-yearold group.

Our differences between immediate and delay conditions can be accounted for in one of two ways. First, MacKay and MacKay (1977) argue that increased aftereffects associated with delay could be due to enhanced readout (they refer to this as refreshment of the sensory mechanism). Second, it is possible that our immediate group underwent some general sort of counterconditioning in the few minutes allowed between adaptation and test. These possibilities await further investigation.

Little is known about the exact mechanisms involved in the formation and subsidence of contingent aftereffects. One notion is that higher order neurons are conjointly activated by lower order ones that process color and pattern information. During adaptation, these synapses are thought to be somehow fatigued. It would logically follow that recovery from such fatigue would occur when adaptation ceased, but numerous experiments have shown that this is not the case. When darkness is interposed between adaptation and test, aftereffects decay only slightly or actually increase in magnitude. The most effective means of restoring preadaptation levels involves stimulating with chromatic gratings of opposite color/orientation pairing to that used during adaptation (Skowbo et al., 1974). The next most effective procedure involves stimulating with achromatic gratings similar to the colored ones used during adaptation. These findings and others (Murch, 1976) have led to the suggestion that such contingent aftereffects consititute a form of associationistic learning, wherein extinction and counterconditioning are effective in reducing the perceptually learned response.

In 1980, Harris reviewed the McCollough effect literature providing evidence for two theoretical models: the adaptation/fatigue model and the associative learning model. He concluded that, although there were some problems with the model, associative learning more parsimoniously explained the McCollough effect. Also, although earlier learning models were based on classical conditioning (Murch, 1976), Harris pointed out that basic associative mechanisms were broader than the limited model of classical conditioning. A less restrictive view of learning, and research on its more basic mechanisms, was suggested to shed further light on contingent aftereffects. More recently, Skowbo and others (Skowbo \& Forster, 1983; Skowbo \& Rich, 1982; Skowbo \& White, 1983) have challenged the learning model of the McCollough effect. It was found that practice did not affect the strength or facilitate the acquisition of the McCollough effect. On the other hand, S. Siegel and Allan (1984) found that orientation-contingent color aftereffects were subject to overshadowing and blocking, thus supporting an associative learning model.

While the outcome of the present study, that children at younger ages experience stronger aftereffects than 10-year-olds and adults, cannot directly support either of these models, it is suggestive of the rapid strides in learning typical of young children. Indirect evidence for the idea that children differ from adults in associative learning capabilities has been provided by studies of incidental learning. These studies employ a paradigm that requires subjects to answer questions based on extraneous information from stimuli employed in memory tasks. This learning has been termed "incidental" because subjects are instructed to concentrate on certain salient aspects of a task, and are then tested for recall or recognition of other minor characteristics of the previously presented stimuli. Cognitive strategies, which generally account for the better performance of older subjects over young children in most learning tasks, are mitigated, thus providing a clearer measure of basic associative learning than do other paradigms. It has been reported that younger children demonstrate greater incidental learning than older adolescents (Hale, Miller, \& Stevenson, 1968; A.W. Siegel \& Stevenson, 1966). Further research into age-related differences in basic associative learning may well provide the needed support for the learning model of the McCollough effect.

\section{REFERENCES}

Abramov, I., Gordon, J., Hendrickson, A., Hainline, L., Dobson, V., LABossiere, E. (1982). The retina of the newborn human infant. Science, 217, 265-267.

BorNSTEIN, M. H. (1981). Two kinds of perceptual organization near the beginning of life. In W. A. Collins (Ed.), Aspects of the develop- 
ment of competence, The Minnesota Symposia on Child Psychology (Vol. 14). Hillsdale, NJ: Erlbaum.

Coren, S., \& Girgus, J. S. (1978). Seeing Is deceiving: The psychology of visual illusions. Hillsdale, NJ: Erlbaum.

Fox, R., Asun, R. N., Shea, S. L., \& Dumais, S. T. (1980). Stereopsis in human infants. Science, 207, 323-324.

Hale, G., Miller, L. K., \& Stevenson, H. W. (1968). Incidental learning of film content. Child Development, 39, 69-78.

HARRIS, C. S. (1980). Insight or out of sight?: Two examples of perceptual plasticity in the human adult. In C. Harris (Ed.), Visual coding and adaptability. Hillsdale, NJ: Erlbaum.

Holding, D. H., \& Jones, P. D. (1975, November). One-trial extinction of the McCollough effect. Paper presented at the meeting of the Psychonomic Society, Denver.

JoNES, P. D., \& HoldiNG, D. H. (1975). Extremely long-term persistence of the McCollough effect. Journal of Experimental Psychology: Human Perception and Performance, 1, 323-327.

KARMel, B. Z., MAISEL, E. B. (1975). A neuronal activity model for infant visual attention. In L. B. Cohen \& P. Salapatek (Eds.), Infant perception: From sensation to cognition (Vol. 1). New York: Academic Press.

KaUfman, J. H., MAY, J. G., \& KuneN, S. (1981). Interocular transfer of orientation-contingent color aftereffects with external and internal adaptation. Perception \& Psychophysics, 30, 547-551.

KUNEN, S., \& MAY, J. G. (1980). Spatial frequency content of visual imagery. Perception \& Psychophysics, 28, 555-559.

MACKAY, D. M., \& MACKAY, V. (1975). What causes decay of patterncontingent chromatic aftereffects? Vision Research, 15, 462-464.

MacKAY, D. M., \& MACKAY, V. (1977). Retention of the McCollough effect in darkness: Storage or enhanced readout. Vision Research, 17, 313-315.

Marg, E., Freeman, D. N., Pheltzman, P., \& Goldstein, P. J. (1976). Visual acuity development in human infants: Evoked potential estimates. Investigative Ophthalmology, 15, 150-153.

May, J. G., Agamy, G., \& MatTeson, H. (1978). The range of spatial frequency contingent color aftereffects. Vision Research, 18. 917-921

MAY, J. G., \& MATtESON, H. (1976). Spatial frequency-contingent color aftereffects. Science, 192, 145-147.

May, J. G., Matteson, H., Agamy. G., \& Castellanos, P. (1978). The effects of differential adaptation on spatial frequency-contingent color aftereffects. Perception \& Psychophysics, 23, 409-412.

McCollough, C. (1965). Color adaptation of edge-detectors in the human visual system. Science. 149. 1115.
Meyer, G. E., Coleman, A., Dwyer, T., \& Lehman, I. (1982). The McCollough effect in children. Child Development, 53, 838-840.

Moskowitz, A., Skarf, B., \& Sokol, S. (1983). Contrast sensitivity in children and young adults. Poster presented at the meeting of the Optical Society of America, New Orleans.

Movshou, J. A., \& VAN SLuYTers, R. C. (1981). Visual neural development. Annual Review of Psychology, 32, 477-522.

MuRCh, G. M. (1976). Classical conditioning of the McCollough effect: Temporal parameters. Vision Research, 16, 615-619.

Pirchio, M., SPinelli, D., Fiorentini, A., \& Maffei, L. (1978). Infant contrast sensitivity evaluated by evoked potentials. Brain Research, 141, 179-184.

Riggs, L. A., White, K. D., \& Eimas, P. D. (1974). Establishment and decay of orientation-contingent aftereffects of color. Perception \& Psychophysics, 16, 535-542.

SalapateK, P. (1975). Pattern perception in early infancy. In L. B. Cohen \& P. Salapatek (Eds.), Infant perception: From sensation to cognition (Vol. 1). New York: Academic Press.

Siegel, A. W., \& Stevenson, H. W. (1966). Incidental learning: A developmental study. Child Development, 37, 811-817.

SiEGEL, S., \& AlLAN, L. G. (1984). Overshadowing and blocking of the orientation-contingent color aftereffect: Evidence for a conditioning mechanism. Manuscript submitted for publication.

SKowbo, D., \& Forster, T. (1983). Further evidence against the classical conditioning model of McCollough effects. Perception \& Psychophysics, 34, 552-554.

Skowbo, D., Gentry, T., Timney, B., \& Morant, R. B. (1974). The McCollough effect: Influence of several kinds of visual stimulation on decay rate. Perception \& Psychophysics, 16, 47-49.

Skowbo, D., \& Rich, J. (1982). Practice does not facilitate acquisition of McCollough effects: Evidence against a learning model. Perception \& Psychophysics, 32, 551-554.

Skowbo, D., Timney, B. N., Gentry, T. A., \& Morant, R. B. (1975). McCollough effects: Experimental findings and theoretical accounts. Psychological Bulletin, 82, 497-510.

Skowbo, D., \& WhITE, K. (1983). McCollough effect acquisition depends on duration of exposure to inducing stimuli, not number of stimulus presentations. Perception \& Psychophysics, 34, 549-551.

(Manuscript received January 16, 1984; revision accepted for publication August 6, 1984.) 